Received $07^{\text {th }}$ August 2019

Accepted $12^{\text {th }}$ October 2019

www.ijpefs.com

\section{A Comparison Study for the use of Mixed Training (Training with Weight and Plyometric) In the Development of the Distinctive Strength Speed as the Players of the Handball.}

\author{
Harbach brahim a, Mokrani Djamel a, ${ }^{\text {, }}$ Benzidane Houcine a, Ibrahim Reda a
}

Abstract: The research aims to the comparison between the impact of the training with weight, plyometric training and mixed training and the development of the distinctive strength speed as the handball players. The experimental method was adopted due to its adequate relation with the research problem, and used the pilot curriculum of four (04) groups, three of them are experimental one is training with weight and second is plyometric training and the third for mixed training, and one is control. The study was applied on a sample of 64 players divided into 16 players of each group. The most important results are the superiority of the training program of the mixed (weights and plyometric) to other programs in the results of the tests under the search. Thus recommends that the researchers and emphasize the use of mixed training for the development of the distinctive strength speed as the players of the handball.

Key Words:training with weight, plyometric training mixed training, distinctive strength speed, players, and handball.

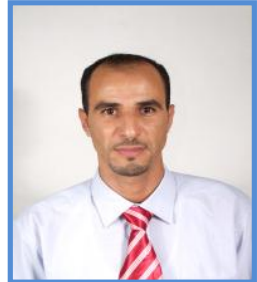

Harbach Brahim (Phd), research Professor of sport sciences in Physical education \& sports institute; University of Mostaganem -Algeria. His research interest includes Theories and methods of physical education and sport. Also, methods of teaching physical education and sport.

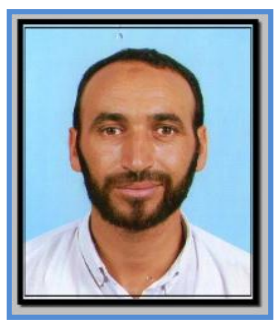

Mokrani Djamel (Pr), research Professor of Physical Education and Sports in University of Mostaganem -Algeria, Through the scientific activities, the doctor directed to research in the field of physical and sports education and was concerned with the impact of the use of several teaching methods in teaching, competency approach, teaching competencies, and we have research in the field of training, handball.

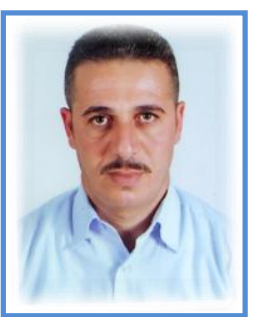

Benzidane Houcine (Pr), research Professor of sport sciences in Physical education \& sports institute; University of Mostaganem - Algeria, member in laboratory of programs optimization in PA\&S. Research interest are sports training education and physical activity and health.

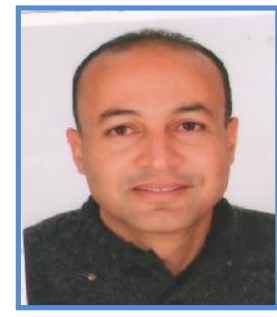

Brahim Reda (Master), professor in Physical education \& sports in secondary level, province of Mostaganem -Algeria, Research interest includes sports training in swimming. 


\section{Mokrani Djamel /2019}

\section{Introduction}

The pace of the sports training strides in through science where the expansion in the use of various building sciences pacification operations, that sports training is the overall process for improvement aimed at sports performance achieved through the planned program to prepare for and rivalries, is the process of the Practice of the Organization is dynamic and constant change.

Longer handball of the collective games browsed since a long time, not a long time had passed occupied its place among other games because it is the speed and enthusiasm. Like the other activities has the game of the handball keep pace with technological using having to find ways and means of efficient, modern and in order to achieve the highest form of access to the highest ranks in the physical performance and competence location good preparation of the physical characteristics of the game, mainly the distinctive strength speed as is a prerequisite something to reach sports to high level featuring the of rapid change and the sudden upsurge in the movement and pellets discus. In order to upgrade the level of this game the focus must be on good preparation for training programs which take into account the requirements of the effective use of the most appropriate and most successful training methods, especially those working on the development of the distinctive strength speed as necessitating the use of several methods to develop such capacity, including training with weight, plyometric training Mixed training. That training with weight has an important role in the development of the muscular strength player of the handball where the nature of the technical performance in this sport require the presence of the force of the fast and therefore training with weight is necessary within the contents of the training programs [1]. The training with weights has an important role in the development of muscle strength of the volleyball player as the nature of the performance skills in this sport requires a force characterized by the speed and then the training with weights is necessary among the contents of training programs [2]

Many researchers also considered that plyometric training methods more commonly used in the development of speed strength (distinctive strengths fast) of many sports activities that require (needs) the integration of the maximum speed with maximum strength of distinctive strengths fast [3] Abdelmaksoud (1997) says that, to reach the maximum degree of efficiency, through the use of strength in different and opposite ways inside the training unit or within range of exercises, and the variation can be reached across the switching between charges through explosive way. Or through change of the degree of charge or the change of contraction type and muscle tension or from training with weights to a Plyometric training [4-5].

Literature review has shown that in the world has made a lot of researches for plyometric method effectiveness and a little bit less researches about plyometric method efficiency for athletes. Most researches main point was to improve and investigate plyometric training effect for the legs. In this research we include also plyometric training effect for the arms. [2]

The Plyometric training techniques are used by athletes in all types of sports to increase strength and explosiveness [3]. Plyometric consists of a rapid stretching of a muscle (eccentric action) immediately followed by a concentric or shortening action of the same muscle and connective tissue. The stored elastic energy within the muscle is used to produce more force than can be provided by a concentric action alone [4].

Moreover also some experts indicates that the importance of plyometric to a strength and conditioning program has previously been established, with positive training adaptations reported for force production (Malisoux,2006), muscular power [5-6].

Many researchers considered that plyometric training is the most commonly methods used in the development of the distinctive strength speed as many sports activities that require the integration of the maximum speed with maximum force for muscle where contribute to easing the guy to overcome the problems that face the development of distinctive strength speed. 


\section{Mokrani Djamel /2019}

The researcher attributed the vertical jump was the best for the plyometric training because of the quick muscle strength use. In other hand the researcher explained this by noticing that the biometrical training consisted on high jump exercises which increase muscles fibers excitability that lead to the involvement of a large number of them giving birth to a strong and fast contraction increasing exploding performance, this is in conformity with what [7-8]. In other hand the mixed training group was the best among all the experimental groups proving the study held by Mokrani .D et al (2017), Mokrani .D et al (2015), Mohamed abd al (2009) which mentioned That the differences between weight training with plyometric has more effect than training separately [9-11].

It also indicates Nahid Adibpour and al (2012) citing some earlier studies as study compared two exercise techniques, weight training and combined training of weights and plyometric exercises. This was carried out on two groups of men for six weeks, three sessions a week. Training group increased their vertical jump by $3.3 \mathrm{~cm}$ and the combined group demonstrated an increase of $7.6 \mathrm{~cm}$. And identical research was carried out on women in the same year by the above researchers. The weight training groups showed an increase of $10.1 \mathrm{~cm}$. carried out other research two sessions a week on two groups for sixteen weeks. The first group performed weight training and plyometric exercises which resulted in an increase of $3.57 \mathrm{~cm}$ in their vertical jump and the second group who only carried out weight training exercises a decrease of $0.11 \mathrm{~cm}$. And all these studies confirm the importance of combining training with weights and plyometric training [12].

Perez-Gomez (2008) evaluated the effect of combined weight training and plyometric exercises on some aspects of physical fitness such as vertical jumping and anaerobic capacity in soccer players in a six-week period and stated that after the training period all players showed significant improvement in vertical jump and anaerobic capacity tests [13].

We have detected during cohabitation field and follow-up to the clear weakness of the fitness center and the players, in particular in the movements of the upgrading of the weakness of the strength of the correction which assured us of the clear shortage in the status of the distinctive strength speed as players, while it is the most important for the player of the handball since its impact on the technical performance player.

The problem of the study which was going on in our mind through field follow-up in the area of training at the level of the teams of national Championship Handball is the lack of diversification, mixing between modern methods of training, particularly in the development of physical characteristics. Although contain programs on weight training when some difference and the emergence of plyometric training of others, but we did not observe the coordination process between the use of these different methods or confused. On this basis the study of trying to make a comparison between the methods of the three training (weight, plyometric, mixed) and normal methods of automatic to learn the best way in the development of the distinctive strength speed as the players of the handball.

Through a proposed training program to identify:

- The effect or the impact of weight training on the distinctive strength speed as the players of the handball.

- The effect of plyometric training on the distinctive strength speed as the players of the handball.

- The effect of mixed training (weight and plyometric) on the distinctive strength speed as the players of the handball.

- The effect of mixed training (weight and plyometric) on the distinctive strength speed as the players of the handball.

- The reciprocity relationship impact between the effect of training with weights and plyometric training and mixed training (weight and plyometric) on the distinctive strength speed as the players of the handball.

\section{Search procedures}

Search approach: Use the researcher experimental approach using four (04) groups of three pilots 


\section{Mokrani Djamel /2019}

(experimental) and one control.

A sample Research: a sample research included on 64 players from classified the clubs are active in four teams of the championship regional of Handball in Algeria. Were divided into four equal groups with a hop count of 16 players of each group.

The first group training with weight, and the second group plyometric training, the third group mixed training (plyometric and weightlifting.) The fourth group is a control

\subsection{Physical tests:}

Three partridge right foot.

Three partridge left foot.

The Front relies on for 10 seconds.

Throw medical ball $3 \mathrm{~kg}$.

Throw medical ball $3 \mathrm{~kg}$.

\subsection{The suggested training program}

Was the preparation of the training programs proposed experimental groups taking into account the following?

\subsubsection{For the group of weight training:}

The intensity of the contraceptive methods used by 50 to $85 \%$ of the Maximum in ability of each individual. The number of occurrences of 03 to 10 duplicates. The number of groups of 04 to 06 . The time of comfort internet work between groups of 90 to 240 seconds. Taking into account the principle of progressivity in distress, quelling through increasing the weight of gravity.

\subsubsection{For the Group of plyometric training:}

The intensity of the contraceptive methods used from 60 to $90 \%$ of the maximum force of the individual.

The number of occurrences of 06 to 10 per group quelling 03 to 04 groups.

The distress is increased through increase of the maximum height of the fund for every individual on an end to the action medical ball be repeat 06 to 12 times in 03 to 05 groups.

The time of comfort internet work between groups of 90 to 240 seconds.

\subsection{The Basic Expérience}

Applied the basic experience for twelve (12) weeks at the rate of three training seance for the week, the time of the séance 90 minutes, taking into account the principles of carrying training. Used the first group weigh training program, the second group plyometric training, the third group applied mixed training combining weigh training and plyometric training any alternate until the end of the experience. The fourth group receives regular training as a group control.

\section{Results}

Table 1 shows the difference between measurements of first experimental sample (Training with weight)

\begin{tabular}{|c|c|c|c|c|c|c|c|}
\hline \multirow{2}{*}{ Groups } & \multirow{2}{*}{$\begin{array}{c}\text { The statistical study } \\
\text { Tests }\end{array}$} & \multicolumn{2}{|c|}{ Pre-test } & \multicolumn{2}{|c|}{ Post-test } & \multirow{2}{*}{$\begin{array}{c}\mathrm{T} \\
\text { Calculated }\end{array}$} & \multirow{2}{*}{$\begin{array}{c}\text { The percentage of } \\
\text { progress }\end{array}$} \\
\hline & & means & SD & Means & SD & & \\
\hline \multirow{5}{*}{$\begin{array}{l}\text { Training with } \\
\text { weight }\end{array}$} & 1.Three partridgeright foot & 3.66 & 0.18 & 4.79 & 0.10 & 22.60 & $30.87 \%$ \\
\hline & 2.Three partridgeleft foot & 3.23 & 0.07 & 4.46 & 0.15 & 18.16 & $38.08 \%$ \\
\hline & 3.The Front rely on for $10 \mathrm{sec}$ & 8.12 & 1.26 & 11.18 & 1.60 & 09.02 & $40.98 \%$ \\
\hline & 4. Throw medical ball 3kg & 3.04 & 0.33 & 3.67 & 0.25 & 06.30 & $20.72 \%$ \\
\hline & 5.Test vertical jump unchanged & 28.12 & 1.52 & 36.31 & 1.57 & 08.38 & $14.90 \%$ \\
\hline
\end{tabular}

Checking table (01), it's obvious that there exist significant differences between calculated averages for both pre-test and post-test sample measurements on whom set of training with weight were applied aiming to 
develop the distinctive strength speed as the players of the handball, where calculated $\mathrm{T}$ was estimated to between 6.30 as the smallest value and 22.60 as the largest value is greater than the value of $\mathrm{T}$ tabular which reached 2.13 at degree freedom 15, level of indication 0.05 which means that there exist a statistically significant difference in favor of the sample post measurement.

Table 2 shows the difference between measurements of second experimental sample (plyometric training)

\begin{tabular}{|c|c|c|c|c|c|c|c|}
\hline \multirow{2}{*}{ Groups } & \multirow{2}{*}{$\begin{array}{c}\text { The statistical study } \\
\text { Tests }\end{array}$} & \multicolumn{2}{|c|}{ Pre-test } & \multicolumn{2}{|c|}{ Post-test } & \multirow{2}{*}{$\begin{array}{c}\mathrm{T} \\
\text { Calculated }\end{array}$} & \multirow{2}{*}{$\begin{array}{c}\text { The } \\
\text { percentage of } \\
\text { progress }\end{array}$} \\
\hline & & means & SD & Means & SD & & \\
\hline \multirow{5}{*}{$\begin{array}{c}\text { Plyometric } \\
\text { Training }\end{array}$} & Three partridge right foot & 3.51 & 0.11 & 4.47 & 0.21 & 17.04 & $27.38 \%$ \\
\hline & Three partridge left foot & 3.21 & 0.06 & 4.18 & 0.20 & 19.41 & $30.21 \%$ \\
\hline & The Front rely on for $10 \mathrm{sec}$ & 8.06 & 1.28 & 12.18 & 1.42 & 07.77 & $51.11 \%$ \\
\hline & Throw medical ball $3 \mathrm{~kg}$ & 3.12 & 0.22 & 3.92 & 0.27 & 06.41 & $25.64 \%$ \\
\hline & Test vertical jump unchanged & 28.25 & 1.49 & 35.12 & 1.58 & 16.35 & $24.31 \%$ \\
\hline
\end{tabular}

We do notice from the table (02) the existence of significant differences between calculated averages of pre and post measurement of the sample on which the set of plyometric exercises were applied aiming to develop the strength characterized by speed for high parties muscles where calculated $\mathrm{T}$ was estimated between to 06.41 and19.41 which is higher to tabulated T that reached 2.13 in the freedom degree of 15 and significant level of 0.05 .Which means that there were significant differences in favor of posttest concerning the research sample.

Table 3 shows the difference between measurements of third experimental sample (mixed training)

\begin{tabular}{|c|c|c|c|c|c|c|c|}
\hline \multirow{2}{*}{ Groups } & \multirow{2}{*}{$\begin{array}{c}\text { The statistical study } \\
\text { Tests }\end{array}$} & \multicolumn{2}{|c|}{ Pre-test } & \multicolumn{2}{|c|}{ Post-test } & \multirow{2}{*}{$\begin{array}{c}\mathrm{T} \\
\text { Calculated }\end{array}$} & \multirow{2}{*}{$\begin{array}{c}\text { The } \\
\text { percentage of } \\
\text { progress }\end{array}$} \\
\hline & & means & SD & Means & SD & & \\
\hline \multirow{5}{*}{$\begin{array}{l}\text { Mixed } \\
\text { training }\end{array}$} & Three partridge right foot & 3.52 & 0.12 & 4.92 & 0.22 & 23.51 & $39.77 \%$ \\
\hline & Three partridge left foot & 3.15 & 0.21 & 4.55 & 0.30 & 19.97 & $44.44 \%$ \\
\hline & The Front rely on for $10 \mathrm{sec}$ & 8.00 & 1.25 & 12.31 & 1.29 & 10.26 & $53.87 \%$ \\
\hline & Throw medical ball 3kg & 3.14 & 0.24 & 4.02 & 0.37 & 06.67 & $28.02 \%$ \\
\hline & Test vertical jump unchanged & 28.06 & 1.52 & 36.06 & 1.48 & 17.39 & $28.51 \%$ \\
\hline
\end{tabular}

We do notice from the table (03) the existence of significant differences between calculated averages of pre and post measurement of the sample on which the set of mixed training (weight and plyometric) were applied aiming to develop the strength characterized by speed for high parties muscles where calculated $\mathrm{T}$ was estimated between to 06.67 and 23.51 which is higher to tabulated $\mathrm{T}$ that reached 2.13 in the freedom degree of 15 and significant level of 0.05 .Which means that there were significant differences in favor of posttest concerning the research sample. 


\section{Mokrani Djamel /2019}

Table 4 shows the difference between measurements of control sample

\begin{tabular}{|c|c|c|c|c|c|c|c|}
\hline \multirow{2}{*}{ Group } & \multirow{2}{*}{$\begin{array}{c}\text { The statistical study } \\
\text { Tests }\end{array}$} & \multicolumn{2}{|c|}{ Pre-test } & \multicolumn{2}{|c|}{ Post-test } & \multirow{2}{*}{$\begin{array}{c}\mathrm{T} \\
\text { Calculated }\end{array}$} & \multirow{2}{*}{$\begin{array}{c}\text { The } \\
\text { percentage of } \\
\text { progress }\end{array}$} \\
\hline & & means & SD & Means & SD & & \\
\hline \multirow{5}{*}{$\begin{array}{l}\text { Control } \\
\text { Group }\end{array}$} & Three partridge right foot & 3.49 & 0.36 & 4.11 & 0.29 & 07.75 & $15.93 \%$ \\
\hline & Three partridge left foot & 3.19 & 0.39 & 3.58 & 0.36 & 07.81 & $12.22 \%$ \\
\hline & The Front rely on for $10 \mathrm{sec}$ & 8.25 & 1.38 & 10.06 & 1.33 & 08.24 & $21.93 \%$ \\
\hline & Throw medical ball 3kg & 2.98 & 0.40 & 3.34 & 0.56 & $04: 50$ & $12.08 \%$ \\
\hline & Test vertical jump unchanged & 28.00 & 1.26 & 30.12 & 1.35 & 14.66 & $07.57 \%$ \\
\hline
\end{tabular}

Checking table (04), it's obvious that there exist significant differences between calculated averages for both pre-test and post-test sample measurements on whom set of traditional training were applied aiming to develop the distinctive strength speed as the players of the handball, where calculated T was estimated to between 04.50 as the smallest value and 14.66 as the largest value is greater than the value 6.30 as the smallest value and 22.60 as the largest value is greater than the value of $\mathrm{T}$ tabular which reached 2.13 at degree freedom 15, level of indication 0.05 which means that there exist a statistically significant difference in favor of the post measurement for sample control.

Table 5 Shows the variance analysis between four groups to discuss the physical tests under study.

\begin{tabular}{|c|c|c|c|c|c|c|}
\hline Tests & $\begin{array}{l}\text { The source of } \\
\text { the Variance }\end{array}$ & $\begin{array}{l}\text { The total } \\
\text { number of } \\
\text { square feet } \\
\text { deviations }\end{array}$ & $\begin{array}{l}\text { The degree } \\
\text { of freedom }\end{array}$ & $\begin{array}{c}\text { The } \\
\text { averages } \\
\text { boxes }\end{array}$ & $\begin{array}{c}\text { F } \\
\text { Calculated }\end{array}$ & $\begin{array}{c}\text { The Indicative } \\
\text { level }\end{array}$ \\
\hline \multirow{2}{*}{$\begin{array}{l}\text { Three partridge } \\
\text { right foot }\end{array}$} & Between groups & 6.27 & \multirow{10}{*}{60} & 2.09 & \multirow{2}{*}{41.8} & \multirow{2}{*}{ Significance } \\
\hline & Within groups & 3.43 & & 0.05 & & \\
\hline \multirow{2}{*}{$\begin{array}{c}\text { Three partridge } \\
\text { left foot }\end{array}$} & Between groups & 9.18 & & 3.06 & \multirow{2}{*}{38.25} & \multirow{2}{*}{ Significance } \\
\hline & Within groups & 4.95 & & 0.08 & & \\
\hline \multirow{2}{*}{$\begin{array}{c}\text { The Front rely on } \\
\text { for } 10 \text { seconds }\end{array}$} & Between groups & 52.39 & & 17.46 & \multirow{2}{*}{8.15} & \multirow{2}{*}{ Significance } \\
\hline & Within groups & 128.68 & & 2.14 & & \\
\hline \multirow{2}{*}{$\begin{array}{c}\text { Throw medical } \\
\text { ball } 3 \mathrm{~kg}\end{array}$} & Between groups & 4.39 & & 1.46 & \multirow{2}{*}{8.58} & \multirow{2}{*}{ Significance } \\
\hline & Within groups & 10.52 & & 0.17 & & \\
\hline \multirow{2}{*}{$\begin{array}{l}\text { Test the vertical } \\
\text { jump unchanged }\end{array}$} & Between groups & 351.68 & & 117.22 & \multirow{2}{*}{46.33} & \multirow{2}{*}{ Significance } \\
\hline & Within groups & 151.80 & & 2.53 & & \\
\hline
\end{tabular}

The value of F Tabular trend display at the level of the significance of the $0.05=2.76$.

It is clear through the results of table (05) differences statistically function at the level of the significance of 0.05 and the degree of freedom (60-3), F Tabular trend display 2.76 The smallest $\mathrm{F}$ calculated each tests this requires the use of the method of Tiokibreach of finding more accurately the moral teams. 


\section{Mokrani Djamel /2019}

Table 6 Shows the significance of the differences between the four groups to discuss the physical tests under study.

\begin{tabular}{|c|c|c|c|c|c|c|c|}
\hline \multirow{2}{*}{ Tests } & \multirow{2}{*}{$\begin{array}{l}\text { The } \\
\text { Groups }\end{array}$} & \multirow{2}{*}{$\begin{array}{c}\text { The } \\
\text { averages }\end{array}$} & \multicolumn{4}{|c|}{ The Groups } & \multirow{2}{*}{$\begin{array}{l}\text { The value of } \\
\text { the HSD }\end{array}$} \\
\hline & & & First & Second & Third & Fourth & \\
\hline \multirow{4}{*}{ Three partridge right foot. } & First & 4.79 & & $0.32 *$ & 0.13 & $0.68 *$ & \multirow{4}{*}{0.19} \\
\hline & Second & 4.47 & & & $0.45^{*}$ & $0.36^{*}$ & \\
\hline & Third & 4.92 & & & & $0.81^{*}$ & \\
\hline & Fourth & 4.11 & & & & & \\
\hline \multirow{4}{*}{ Three partridge left foot. } & First & 4.46 & & $0.28 *$ & 0.09 & $0.88^{*}$ & \multirow{4}{*}{0.12} \\
\hline & Second & 4.18 & & & $0.37 *$ & $0.60 *$ & \\
\hline & Third & 4.55 & & & & $0.97^{*}$ & \\
\hline & Fourth & 3.58 & & & & & \\
\hline \multirow{4}{*}{ The Front rely on for $10 \mathrm{sec}$} & First & 18 & & $1 *$ & $1.13^{*}$ & $1.12^{*}$ & \multirow{4}{*}{0.62} \\
\hline & Second & 12.18 & & & 0.13 & $2.12^{*}$ & \\
\hline & Third & 12.31 & & & & $2.25^{*}$ & \\
\hline & Fourth & 10.06 & & & & & \\
\hline \multirow{4}{*}{ Throw of medical ball 3kg. } & First & 3.67 & & 0.25 & 0.35 & 0.33 & \multirow{4}{*}{0.36} \\
\hline & Second & 3.92 & & & 0.1 & $0.58^{*}$ & \\
\hline & Third & 4.02 & & & & $0.68^{*}$ & \\
\hline & Fourth & 3.34 & & & & & \\
\hline \multirow{4}{*}{$\begin{array}{c}\text { Test the vertical jump } \\
\text { unchanged. }\end{array}$} & First & 32.31 & & $2.81 *$ & $3.75^{*}$ & $2.19 *$ & \multirow{4}{*}{1.35} \\
\hline & Second & 35.12 & & & 0.91 & $5^{*}$ & \\
\hline & Third & 36.06 & & & & $5^{*}$ & \\
\hline & Fourth & 30.12 & & & & & \\
\hline
\end{tabular}

In table (06), it is clear that the differences between the training with weight and plyometric training and control group in the Test throw the medical ball and not a function of the statistically, as well as between the group of plyometric training and mixed training. While differences statistically function in the rest of the tests between group training with weight and control group in favor of training with weight. The group of training for weight and plyometric training favor of plyometric training, and the group of mixed training and plyometric in favor of a mixed training.

\section{Discussion}

Through tables (01), (02), (03), (04), it is clear that there is no difference between the four groups of experimental and control, which confirms the homogeneity of the sample. And through Table
(05) reflected differences statistically function between measurements and exposit assessments of each group in favor of a posteriori measurements in the tests under discussion. As we see the differences 


\section{Mokrani Djamel /2019}

statistically function when the control group for dimensional test, the researcher was due to the impact of the training leading but the improvement was slight.

The plyometric training package came with statistical differences function in the development of the distinctive force speed, the same with the group training keep this is agreed with the study of [1-2] . Came also differences statistically function when the group of mixed training for dimensional measurement and this is what was also agreed with the study [9]. Through the receivers clear the extent of the progress which confirms that the method of training proposed mixed effective in the development of the distinctive strength speed where [14]. The need to use the mixed training throughout the season training program. Thus when discussing the first assumption results obtained confirm the authenticity of the assumption was says that there are differences statistically function between pre-test and post-test each group separately for post-test.

In the test of three partridge right foot and three partridge left foot we see the superiority of the training with weight set on the plyometric training this is consistent with the nature of the activist performance of the game of handball in deception and corrigendum of long jump. and in the test front rely on for 10 seconds came differences statistically function between four groups only between the plyometric training and mixed training, a group training with weight the best of the control group. The group of plyometric training is the best than of the training with weight. It came also differences statistically function on behalf of the group of mixed training compared with the weight training, which confirms that the differences came for an improvement in favor of a mixed training that is consistent with the study of $[8,10-11]$.

In the test of throw medical ball came distinctions no significance between the training with weight and plyometric training, and between the group training with weight and mixed training, and between group plyometric training and control group. While differences statistically function between the plyometric group and of training control group in favor of plyometric training. It came also differences statistically function between the group of mixed training and control group in favor of mixed training. This is consistent with the study of [12] where confirm that the impact of the training of the mixed (weightlifting and plyometric) is more effective for every training.

In the test vertical jump came differences statistically function between the training with weight and plyometric training, and the group of plyometric and mixed training, as well as between the group of mixed training and control group. This is consistent with the study of [8,13-17, 19] the researcher confirms that vertical jump was better for plyometric training because of the use of speed and employment muscular strength compared to weight training. Through the above we found that the health of the imposition of a second confirms the progress of a mixed training on the rest of the experimental groups and control group.

\section{Conclusions}

Training with weight, plyometric training and mixed training have a paramount importance in the development of the distinctive strength speed as of the handball players. Training with weight is necessary to develop the partridge, jumping and is best rather than plyometric training. Plyometric training is necessary to develop the capacity and muscle skeletal disorders of the two men, especially in vertical jump. Also, Plyometric training is necessary to develop the vertical jump and better than keep training. Mixed training (weightlifting and plyometric) is more influent than all the training on the draw down in the tests under study.

\section{References}

[1] Abdelaziz Nemre, The effect of weight training program on muscle growth rates, exercise science and art journal, published, Faculty of physica education for girls in Al Aziziyah, Cairo, 3 (1991) 68.

[2] Abuzaid Imadeddine. Plans and scientific basis to built a team in collective games. Alexandria. Knowledge center,(2005). 


\section{Mokrani Djamel /2019}

[3] Bastawisi Ahmed. Foundations and Theories of Sports Training. Cairo: Dar El-fikr ElArabi,(1997).

[4] D.A. Chu, Jumping into plyometric, 2nd edition, Human Kinetics, Champaign, IL, (1998).

[5] Abdelmaksoud. A. sports training theories. Cairo. the book publishing center,(1997) 131

[6] Malisoux L, Francaux M, Nielens H, and Theisen D. Stretch-shortening cycle exercises: An effective training paradigm to enhance power output of human single muscle fibers. J Appl Physiol 100(2006) 771- 779.

[7] K. Thomas, D. French, P.R. Hayes, The effect of plyometric training techniques on muscular power and agility in youth soccer players, The Journal of Strength \& Conditioning Research, 23 (2009) 332-33

[8] C. Kotzamanidis, Effect of Plyometric training on running performance and vertical jumping in prepubertal boys, Journal of Strength and Conditioning Research , 20 (2006) 441- 445.

[9] Mokrani Djamel, Benzidane Houcine, Hadjar Kharfane Mohamed. Training with Weights and Plyometric Training, and Their Impact on the Development of Certain Physical Qualities in Shooting in Extension for Handball Players, The Russian Journal of Physical Education and Sport, 12 (2017) 14-20.

[10] Mokrani djamel, Benzidane Houcine, Sebbane Mohammed, Tahar, The reciprocal Relationship between training with weights and the bliometric training and their effect on the muscles capacities growth for basketball players, European journal of physical education and sport, 8 (2015) 90-96.

[11] Mohamed Abdel Aal, The effect of using training with weights plyometric and mixed on the dynamic evolution of muscle power and digital achievement for the long jump competition, published, scientific theories and applications journal, College of physical education, Alexandria, 39 (2000).

[12] Nahid Adibpour, Hojatolah NikBakht and Naser Behpour, Comparison of the Effect of
Plyometric and Weight Training Programs on Vertical Jumps in Female Basketball Players, World Journal of Sport Sciences, 7 (2012) 99104.

[13] J.P.G.J. Perez-Gomez, Effects of weight lifting training combined with plyometric exercises on physical fitness, body composition and knee extension velocity during kicking in football, Applied Physiology, Nutrition and Metabolism, 33 (2008) 501-510.

[14] Talha husam et al., Scientific encyclopedia in athletic training, cairo, The book publishing center .(1999).

[15] Houcine Benzidane, DjamelMokrani, Koutchouk Sidi Mohamed, Asli Houcine, Zerguine Sadek, Efect of using some plyometrics exercises to improve explosive power and digital achievement in the long jump, European Journal of Physical Education and Sport Science, 1(2016)153-156.

[16] Zabchi noureldine, Mokrani Djamel, Benzidane Houcine, Sebbane Mohamed, The effect of the contrastive training using weights and plyometrics on the development of the vertical jump ability to improve the performance of the Smatch for volleyball players, European Journal of Physical Education and Sport, 1 (2016) 24-30.

[17] G. Fatouros, Ioannis, Z. Jamurtas, Athnasios, D. Leontsini, Taxildaris, Kyriakos, N. Aggelousis, Buckenmeyer, Philip. Evaluation of Plyometric Exercise Training, Weight Training, and Their Combination on Vertical Jumping Performance and Leg Strength, Journal of Strength \& Conditioning Research, 14 (2000) 470-476.

[18] V. Marginson, A. Rowlands, N. Gleeson, R. Eston, Comparison of the symptoms of exerciseinduced muscle damage after an initial and repeated bout of Plyometric exercise in men and boys, Journal of Applied Physiology, 99 (2005) 1174-1184.

[19] D. Matavul M. Kukolj, J. Ugarkovic, J. Tihanyi, S. Jaric, Effects of Plyometric training on jumping performance in junior basketball players, Journal of Sports Medicine and Physical Fitness, 41 (2001) 159-164. 


\section{Funding}

This study was not funded by any grant

\section{Acknowledgments}

Our thanks and appreciation to the Presidents and trainers and Players in clubs in of the championship regional of Handball in Algeria to participate in the completion of research.

\section{Conflicts of interest}

The authors certify that there is no conflict of interest with any financial organization regarding the material discussed in the manuscript; we were not funded from any institution.

\section{Informed consent}

All participants gave written informed consent to participate in this study.

\section{About The License}

\section{()(1)}

Attribution 4.0 International (CC BY 4.0)
The text of this article is licensed under a Creative Commons Attribution 4.0 International License 